\title{
Surface Modification of Gentamicin-loaded Polylactic Acid (PLA) Microsphere Using Double Emulsion and Solvent Evaporation: Effect on Protein Adsorption and Drug Release Behaviour
}

\author{
Normahira Mamat, ${ }^{1,2}$ Mariatti Jaafar ${ }^{1 *}$ and Zuratul Ain Abdul Hamid ${ }^{1}$ \\ ${ }^{1}$ School of Materials and Mineral Resources Engineering, Universiti Sains Malaysia, \\ Engineering Campus, 14300 Nibong Tebal, Pulau Pinang, Malaysia \\ ${ }^{2}$ School of Mechatronic Engineering, Universiti Malaysia Perlis, \\ Pauh Putra Campus, 02600 Arau, Perlis, Malaysia \\ *Corresponding author: mariatti@usm.my
}

Published online: 15 February 2019

To cite this article: Mamat, N., Jaafar, M. \& Abdul Hamid, Z. A. (2019). Surface modification of gentamicin-loaded polylactic acid (PLA) microsphere using double emulsion and solvent evaporation: Effect on protein adsorption and drug release behaviour. J. Phys. Sci., 30(Supp. 1), 109-124, https://doi.org/10.21315/jps2019.30.s1.7

To link to this article: https://doi.org/10.21315/jps2019.30.s1.7

\begin{abstract}
Polylactic acid (PLA) microsphere as a drug carrier has been extensively investigated for drug delivery systems. However, due to its limitation of surface hydrophobicity, surface modifications have been studied to improve its utilisation in tissue engineering applications. In the present study, PLA microsphere loaded with gentamicin (GENMS) was modified to enhance its hydrophilicity by surface treatment with additional of ethanol. Ethanol was applied as a co-treating medium in alkaline hydrolysis of $\mathrm{NaOH}$ to assist the hydroxide nucleophilic attack on the ester bond of PLA. Alkaline concentrations of $\mathrm{NaOH}$ and $\mathrm{NaOH} /$ ethanol was set at $0.15 \mathrm{M}, 0.25 \mathrm{M}$ and $0.35 \mathrm{M}$. After surface treatment, hydrophilicity of GENMS surface were improved significantly whereby contact angle was reduced for about $23.1 \%$ and $26.8 \%$ for modification using $\mathrm{NaOH}$ and $\mathrm{NaOH}$ /ethanol, respectively, compared with the neat GENMS. Obvious surface roughness presented by NaOH/ethanol modification improved hydrophilicity of GENMS. As a result, protein adsorption on the GENMS surface treated by NaOH/ethanol were reduced than $\mathrm{NaOH}$ modification. Moreover, the highest encapsulation efficiency by NaOH/ethanol modification provided an advantage of co-treating by ethanol and has a greater drug release compared with $\mathrm{NaOH}$ modification.
\end{abstract}

Keywords: Polylactic acid, microsphere, ethanol, hydrophilicity, modification 


\section{INTRODUCTION}

Local antibiotic release is aimed to prevent implant-associated infections by reducing the bacteria adherence at the implantation site. The utilisation of carriers for local antibiotic release is essential to control drug release at predetermined amount of drug in a predictable manner over a specified time. Microspheres have been extensively studied for the past few decades as a targeted drug delivery device in tissue engineering applications. The use of biocompatible and biodegradable polymers as microspheres have been widely used in drug delivery systems. ${ }^{1-3}$ The most commonly used biodegradable polymers were polylactic acid (PLA) and poly(D, L-lactide-co-glycolide) (PLGA) and poly(e-caprolactone) (PCL) ${ }^{4,5}$

Many studies indicate that PLA formulations containing therapeutic agents exhibit no adverse tissue reaction, either locally or systemically when used in therapeutic applications. ${ }^{6,7}$ Generally, biodegradable polymeric carriers can be degraded via chemical hydrolysis and easily resorbed or eliminated. PLA is an aliphatic polyester. According to Da Silva et al., PLA is considered biocompatible since there was no toxic or carcinogenic substances release to biological environment during their bulk degradation. ${ }^{8}$

However, the consideration on its surface biocompatibility is very important since the microspheres deal with the interfaces between implanted biomaterial and host environment. It is well known that the surface properties of PLA are relatively hydrophobic resulted to ineffective to interact specifically with cells. ${ }^{4}$ It also does not possess any functional groups for the attachment of biologically active molecules. Thus, these shortcomings restricted the application of PLA in bone tissue engineering.

Hydrophobic surfaces are having higher adsorption of proteins and denaturation of proteins at the surface. This leads to exposure of new epitopes which are believed to be a cause of immune reactions towards hydrophobic materials. ${ }^{9}$ On the other hand, a highly hydrophilic surface may expel any protein molecules and inhibit protein adsorption. Hydrophilic surfaces are therefore preferred for microspheres aiming on cell interaction in the host implantation.

Many surface modification techniques, such as silanisation, radiation and photo-grafting techniques, and alkali hydrolysis treatment have been developed for improving the cell affinity of polymers. ${ }^{10-12}$ Among them, alkali hydrolysis treatment is a feasible and convenient method. After surface hydrolysis of aliphatic polyester, the hydrophilic carboxyl and hydroxyl could be produced with cleavage of the ester bonds. However, strong alkali treatment is accompanied by extended 
bulk degradation of the polyester and it was shown that a mild alkali treatment at concentration $0.5 \mathrm{M}$ and above could not break the ester bonds effectively in a short time.${ }^{13}$ Previous study reported that a mixture of sodium hydroxide $(\mathrm{NaOH})$ and acetonitrile can be applied to modify the surface properties of poly(ethylene terephthalate) films and membranes in which acetonitrile was used as a co-treating medium. ${ }^{14}$ However, acetonitrile is expensive, toxic and pollution of the environment cannot be neglected. Study by Yang et al. showed that the hydrophilicity of poly (L-lactic acid) or PLLA was improved by indicating of contact angle that lowered about $39^{\circ}$ after treating with additional of ethanol in $\mathrm{NaOH} .{ }^{13}$ In addition, changes in the bulk and surface of microsphere caused by hydrolysis will not only affect the bulk physical properties of the microsphere, but also release the encapsulated drug in the microsphere via diffusion. ${ }^{7}$

Considering mild concentration of aqueous $\mathrm{NaOH}$ solution used in previous study, present study is aimed to use low concentration and mixture of aqueous $\mathrm{NaOH}$ and ethanol to modify the surface properties of gentamicin GEN-loaded PLA microsphere (GENMS). Here, non-toxic and cheap ethanol was used as co-treating medium. GEN was used in the study due to its most common antibiotics for bone replacement and provides the wide antibacterial spectrum. PLA microspheres were fabricated using single emulsion and solvent evaporation (ESE) technique. The GENMS were produced by double ESE method since this technique can produce microspheres with controlled-release profile using different biocompatible waterinsoluble polymers. ${ }^{15}$ The changes of surface properties and morphology were investigated by scanning electron microscopy (SEM), water contact angle and surface energy, protein adsorption and drug release profile.

\section{EXPERIMENTAL}

\subsection{Materials}

In fabrication of drug-loaded microsphere, PLA microspheres was fabricated by PLA pellet, purchased from Nature Works. Dichloromethane (DCM) was purchased from Merck Millipore and poly(vinyl) alcohol (PVA, 80\% hydrolysis) was acquired from Sigma Aldrich. Ethanol (95\%), sodium hydroxide $(\mathrm{NaOH})$ and hydrochloric acid ( $\mathrm{HCl}, 37 \%$, fuming acid) from Sigma Aldrich were used to modify the surface of fabricated drug-loaded PLA microspheres. Gentamicin (GEN) reagent solution $\left(10 \mathrm{mg} \mathrm{ml}^{-1}\right)$ as encapsulated drug was purchased from Gibco, Life Technologies. Distilled water was used as liquid medium. Bovine serum albumin (BSA, A2058-1G, $40 \mathrm{mg} \mathrm{ml}^{-1}$ water soluble) for protein adsorption test was purchased from Sigma Aldrich. 


\subsection{Fabrication of Gentamicin-loaded PLA Microsphere}

PLA microspheres were fabricated using single emulsion and solvent evaporation (ESE) technique while for GENMS, double ESE was used. In this study, the dispersed phase volume ratio of 1:3 (PLA: PVA) was constructed in fabricating PLA microsphere. Firstly, $2.7 \mathrm{~g}$ of PLA pellets was dissolved in $30 \mathrm{ml}$ DCM and followed by dispersion of $1 \mathrm{ml} \mathrm{GEN} \mathrm{solution} \mathrm{(with} \mathrm{concentration} \mathrm{of} 10 \mathrm{mg} \mathrm{ml}^{-1}$ or $10000 \mathrm{ppm}$ ). This solution is subjected to vigorous homogenisation to yield the primary emulsion. Then the primary emulsion was immediately emulsified into $90 \mathrm{ml}$ PVA solution. The mixtures were stirred at $\sim 1250 \mathrm{rpm}$ for $3 \mathrm{~min}$ to form secondary emulsion at room temperature. Then, the speed of the stirrer was decreased to $\sim 250 \mathrm{rpm}$ for overnight to allow the evaporation of DCM. The particles of the PLA were formed at the bottom of the flask and was washed, filtered and dried overnight at room temperature before the fabricated microspheres were collected. Figure 1 shows double ESE process to produce GENMS.

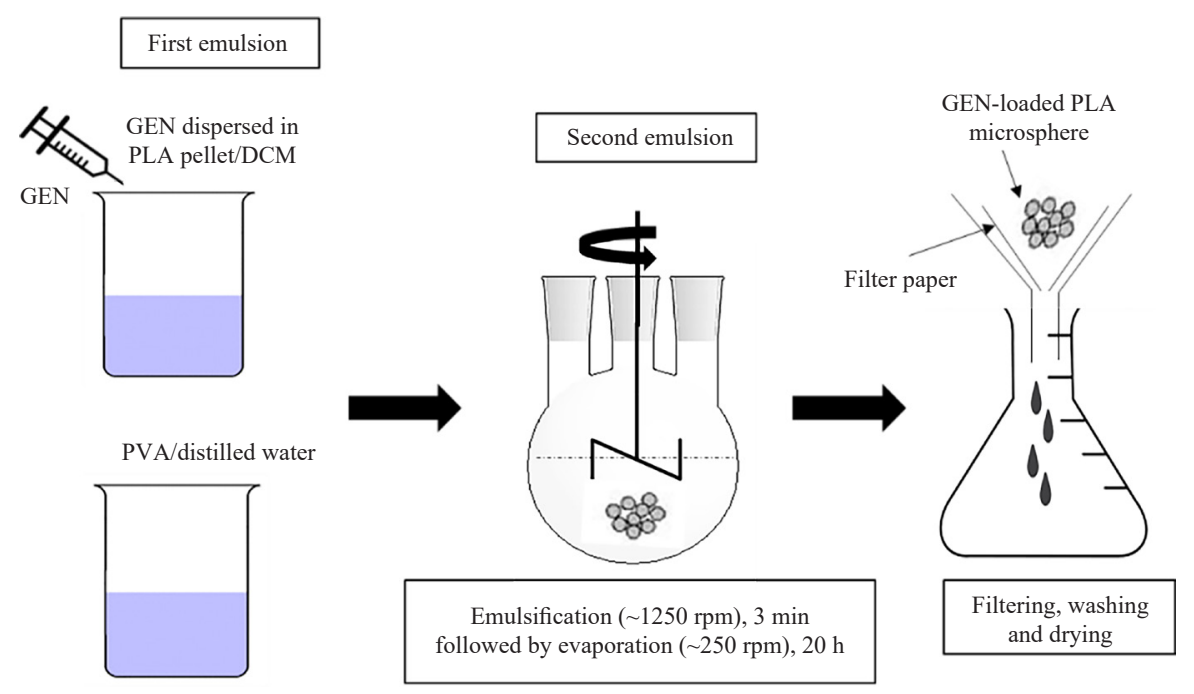

Figure 1: Schematic of double ESE process to produce GENMS.

\subsection{Surface Modification by Alkaline Hydrolysis}

After preparation of PLA microspheres, surface hydrolysis treatment was performed to modify surface and introduce functionality on PLA microsphere. The microspheres were immersed in $\mathrm{NaOH}$ or $\mathrm{NaOH} /$ ethanol solutions for $24 \mathrm{~h}$ with $0.15 \mathrm{M}, 0.25 \mathrm{M}$ and $0.35 \mathrm{M}$ concentration each. After immersion in $\mathrm{NaOH}$ or $\mathrm{NaOH} /$ ethanol, neutralisation was done by immersing treated microspheres in $\mathrm{HCl}$ for $2 \mathrm{~h}$ followed by repeated washing with $500 \mathrm{ml}$ distilled water before being 
dried for overnight. In this study unmodified PLA microsphere was denoted as neat GENMS while modified PLA microsphere was denoted as modified GENMS (with $\mathrm{NaOH}$ or $\mathrm{NaOH} /$ ethanol).

\subsection{Protein Adsorption on Neat GENMS and Modified GENMS using BSA}

The protein solutions were prepared by directly dissolving BSA into deionised water with $\mathrm{pH}$ 7.4. The prepared concentration of BSA was $0.5 \mathrm{mg} \mathrm{ml}^{-1}$. Adsorption analysis were carried out by contacting $0.08 \mathrm{~g}$ of microspheres (neat GENMS and modified GENMS) with a $10 \mathrm{ml}$ solution of $0.5 \mathrm{mg} \mathrm{ml}^{-1}$ BSA concentration in glass vial. After $40 \mathrm{~min}$ whereby, the microspheres were pulled down at the bottom of bottle, $\mathrm{C}_{\text {initial }}\left(C_{i}\right)$ of each sample was measured using UV-VIS at $279 \mathrm{~nm}$ of BSA absorbance intensity. After that, the mixtures were left for $24 \mathrm{~h}$ for $\mathrm{C}_{\text {equilibrium }}\left(C_{e}\right)$. The readings of concentration were based on standard curve plotted as shown in Figure 2.

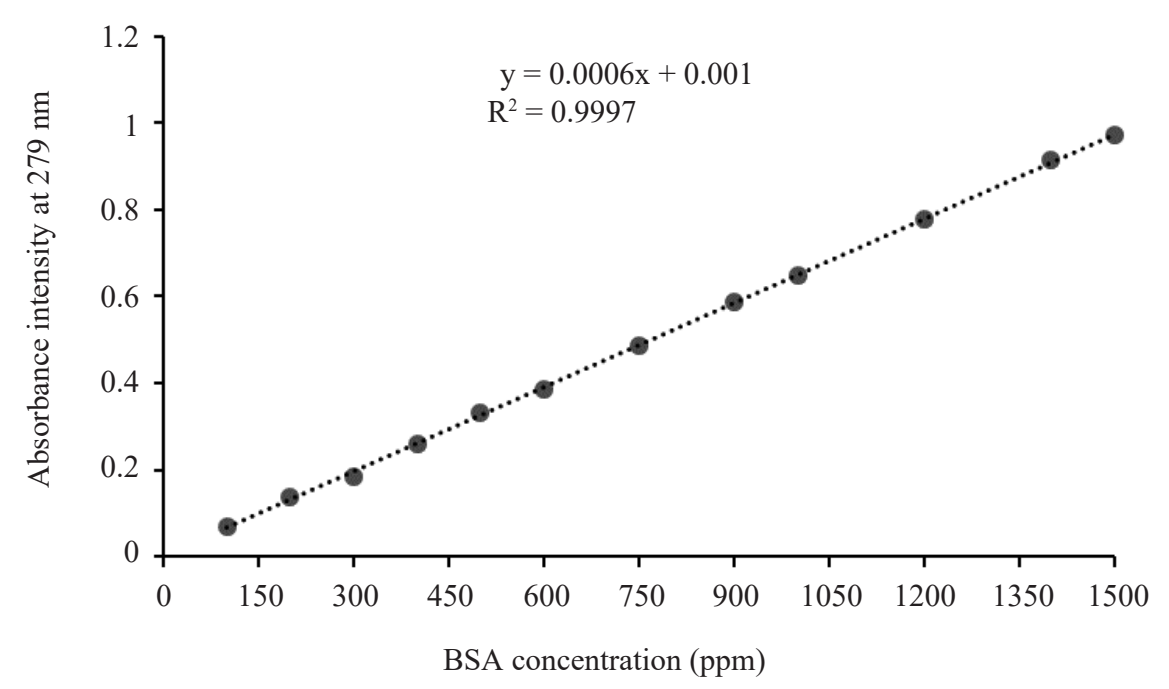

Figure 2: Standard curve of BSA from absorbance intensity at $279 \mathrm{~nm}$ and BSA concentration of 100-1500 ppm.

The adsorption amount $\left(q, \mathrm{mg} \mathrm{g}^{-1}\right)$ was calculated based on Equation $1:^{16}$

$$
q=\frac{\left(C_{i}-C_{e}\right) V}{W}
$$

where $C_{i}$ and $C_{e}\left(\mathrm{mg} \mathrm{m}^{-1}\right)$ are the initial concentration of protein and the concentration of protein at adsorption equilibrium, respectively, $V(\mathrm{ml})$ is the volume of protein solution and $W(\mathrm{~g})$ is the weight of microspheres. 


\subsection{Percentage of Encapsulation Efficiency and Drug Loading of Neat GENMS and Modified GENMS}

In order to determine the encapsulation efficiency, PLA microspheres loaded with gentamicin at weight $40 \mathrm{mg}$ were fully degraded in $5 \mathrm{ml}$ of $1 \mathrm{M} \mathrm{NaOH}$ solution. The samples were left overnight until it was fully degraded and ultraviolet (UV) visible spectroscopy was conducted to determine the percentage of encapsulation efficiency and drug loading of the GEN. Through a scanning of absorbance intensity of GEN at $195 \mathrm{~nm}$ wavelength, a standard curve was plotted with known concentration of 10-400 ppm (Figure 3). The calculation of EE\% and DL\% of the GEN were calculated using Equations 2, 3 and 4.

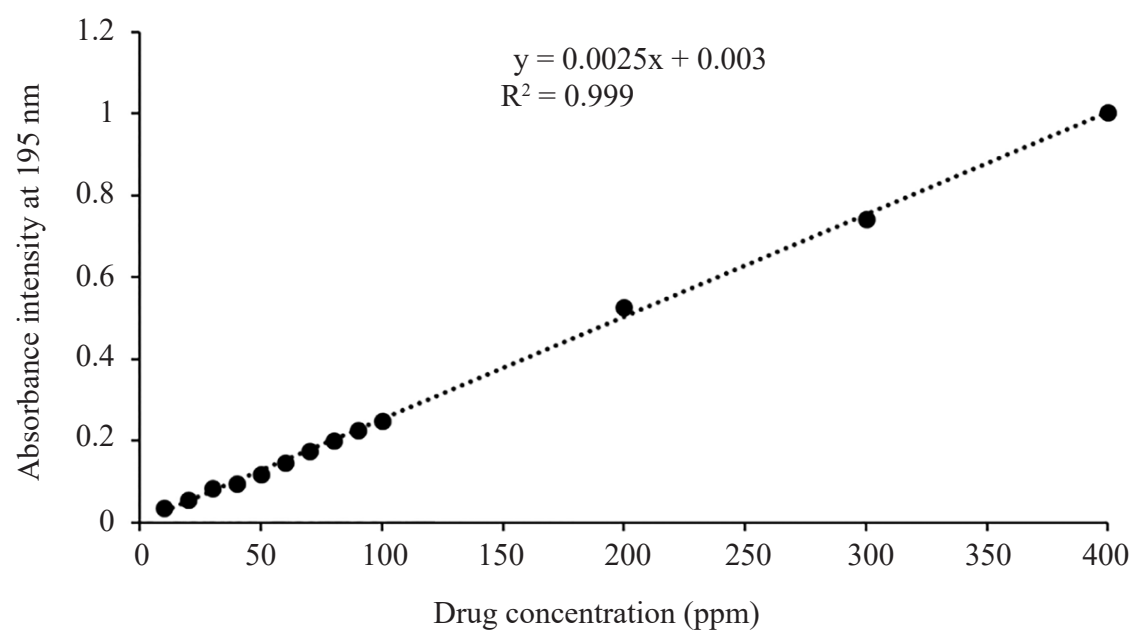

Figure 3: Standard curve of GEN from absorbance intensity at $195 \mathrm{~nm}$ and GEN concentration of 10-400 ppm.

Encapsulated drug mass $(\mathrm{mg})=\frac{\text { Concentration from data }(\mathrm{ppm}) \times 1 \mathrm{ml}}{1000}$

Encapsulated Efficiency $(\%)=\frac{\text { Encapsulated drug mass }(\mathrm{mg}) \times 100}{\text { Initial drug mass }}$

Drug loading $(\%)=\frac{\text { Encapsulated drug mass }(\mathrm{mg}) \times 100}{\text { Microsphere }(\mathrm{g}) \times 1000}$

\subsection{Drug Release Assessment}

The drug release of neat and modified GENMS was measured by dispersion of $30 \mathrm{mg}$ PLA microsphere in $0.1 \mathrm{M}$ of $10 \mathrm{ml}$ PBS in glass vial. Then, the glass vials were placed in shaker with $60 \mathrm{rpm}$ at constant temperature of $37^{\circ} \mathrm{C}$. 
At pre-determined time intervals, aliquots of $3 \mathrm{ml}$ from each sample were extracted and replenished with fresh PBS solution. This is to maintain the total volume of $10 \mathrm{ml}$. The level of GEN in the elution was detected by UV-Vis spectrophotometer at a wavelength of $195 \mathrm{~nm}$.

\subsection{Surface Characterisation}

\subsubsection{Morphology}

Before observation, samples were coated with gold $(\mathrm{Au})$. Surface morphology of PLA microspheres before and after surface modification were evaluated using scanning electron microscope (SEM, Zeiss Supra 55VP, Germany).

\subsubsection{Contact angle measurement}

Contact angle, $\theta$, is a quantitative measure of wetting of a solid by a liquid. This test is used to determine hydrophobicity or hydrophilicity of the neat GENMS and modified GENMS by using ramé-hart instrument co. with DROPimage software. Distilled water was used as a contact medium.

\section{RESULTS AND DISCUSSION}

Figure 4 shows the bulk shape morphology of neat GENMS fabricated by double ESE technique. The images show that the method is able to produce almost perfect spherical microspheres with a uniform surface morphology.

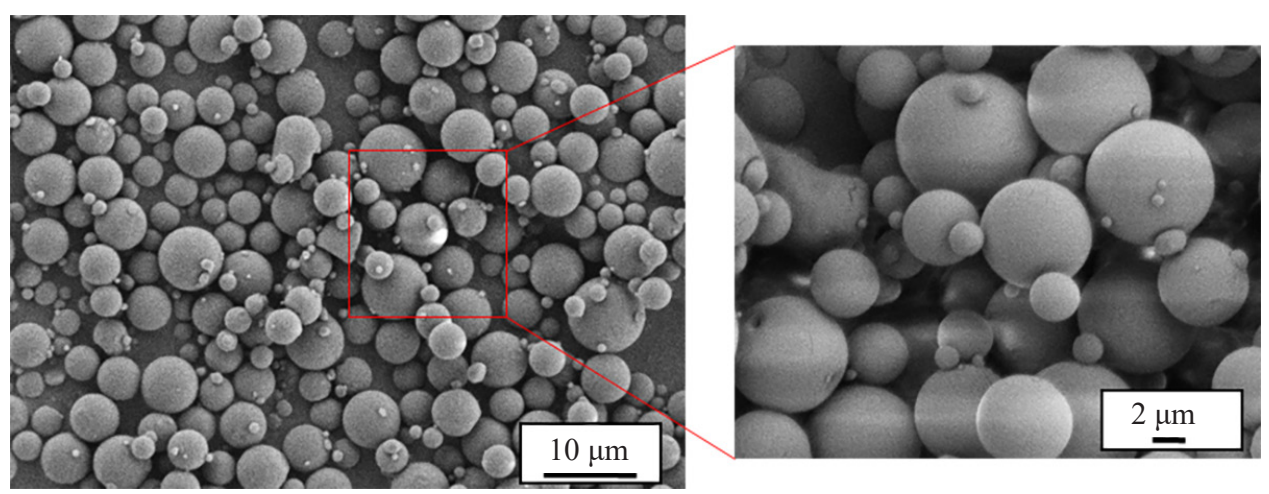

Figure 4: Size of neat GENMS fabricated through double emulsion ESE technique. Images were observed at 1500X (left) and 3000X (right). 
Figure 5 shows SEM images of surface morphology of modified GENMS with $\mathrm{NaOH} /$ ethanol (b, $d$ and $\mathrm{f}$ ) were observed much rougher with small pores existed on their surface than those of modified GENMS with $\mathrm{NaOH}$, shown in Figure 4 (a, c and e). As can be seen, at higher alkaline concentration of $0.35 \mathrm{M} \mathrm{NaOH}$ and $\mathrm{NaOH} /$ ethanol, surface of the microsphere changed to rougher and ripple morphology compared to those $0.15 \mathrm{M}$ and $0.25 \mathrm{M}$ concentrations. In addition, the hydrophilic polar hydroxide and carboxyl groups originating from the cleavage of the surface ester bonds during hydrolysis increased the surface roughness. Swamy et al. reported that the pores on microsphere surface could help in drug release by diffusion mechanism. ${ }^{15}$ Furthermore, the roughness of the material surface greatly influence the cell attachment and cell growth on the material. ${ }^{13}$
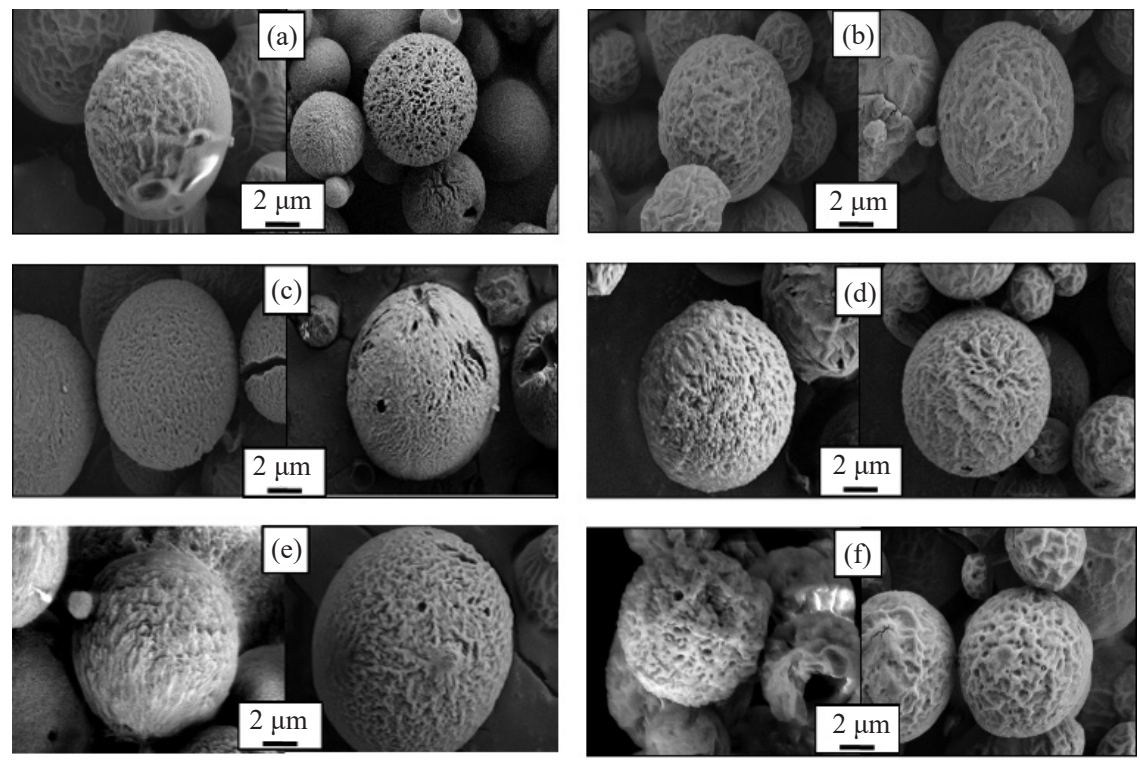

Figure 5: SEM images of modified GENMS with (a) $0.15 \mathrm{M} \mathrm{NaOH}$, (b) $0.15 \mathrm{M} \mathrm{NaOH} /$ ethanol (c) $0.25 \mathrm{M} \mathrm{NaOH}$, (d) $0.25 \mathrm{M} \mathrm{NaOH} /$ ethanol, (e) $0.35 \mathrm{M} \mathrm{NaOH}$ and (f) $0.35 \mathrm{M} \mathrm{NaOH} /$ ethanol.

The wettability of a solid surface is usually expressed by the contact angle and surface energy and it is closely related to the surface morphology. ${ }^{17}$ Water contact angle measured the hydrophobicity or hydrophilicity of neat GENMS and modified GENMS, with more hydrophilic GENMS having smaller water contact angles. Figure 6 shows the drop profiles of water on the surfaces of modified GENMS with $\mathrm{NaOH}$ and $\mathrm{NaOH} /$ ethanol while neat GENMS is used as a reference. Table 1 represents the contact angle measurement and surface energy of modified GENMS. Modified GENMS with $\mathrm{NaOH} /$ ethanol indicated that contact angle was lower (more hydrophilic) than that of $\mathrm{NaOH}$. 


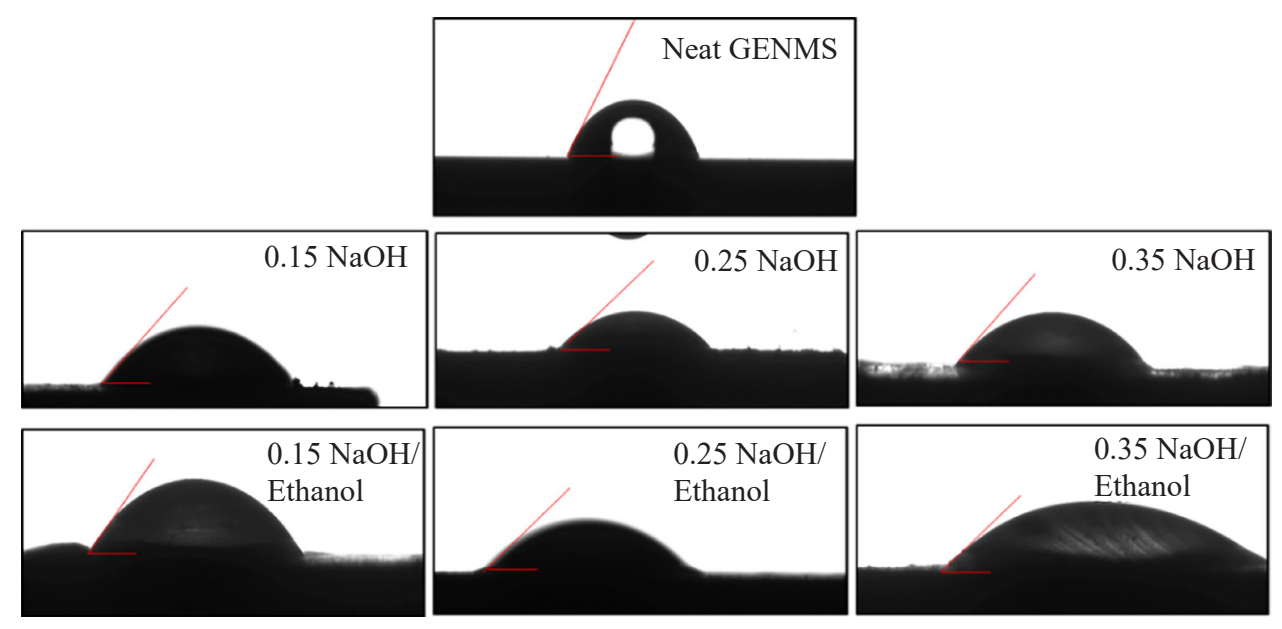

Figure 6: Optical images of drop profiles of neat GENMS and modified GENMS.

Table 1: Contact angle and surface energy of modified GENMS.

\begin{tabular}{lccc}
\hline \multicolumn{2}{l}{ Concentration $(\mathrm{M})$} & Contact angle & Surface energy \\
\hline \multicolumn{2}{l}{ Neat GENMS } & $70.65 \pm 0.02$ & $41.31 \pm 0.01$ \\
0.15 & $\mathrm{NaOH}$ & $58.36 \pm 0.06$ & $48.82 \pm 0.04$ \\
& $\mathrm{NaOH} /$ ethanol & $55.03 \pm 0.02$ & $50.81 \pm 0.01$ \\
0.25 & $\mathrm{NaOH}$ & $52.25 \pm 0.36$ & $52.45 \pm 0.21$ \\
& $\mathrm{NaOH} /$ ethanol & $51.07 \pm 0.60$ & $57.47 \pm 0.03$ \\
0.25 & $\mathrm{NaOH}$ & $52.49 \pm 0.33$ & $52.31 \pm 0.19$ \\
& $\mathrm{NaOH} /$ ethanol & $49.88 \pm 0.24$ & $53.83 \pm 0.14$ \\
\hline
\end{tabular}

The contact angles were reduced by $26.8 \%$ and $23.1 \%$ after treated using $\mathrm{NaOH}$ and $\mathrm{NaOH} /$ ethanol, respectively comparing to neat GENMS. It indicated that the hydrophilicity of GENMS was enhanced by treatment with $\mathrm{NaOH} /$ ethanol mixture due to modification of the surface by increasing the roughness and introducing pores. This is because ethanol was found to assist the hydroxide nucleophilic attack on PLA's ester bonds. ${ }^{13}$ A lower water contact angle of modified GENM with $\mathrm{NaOH} /$ ethanol was also supported by its high surface energy $\left(51-58 \mathrm{~mJ} \mathrm{~m}^{-2}\right)$ than those with $\mathrm{NaOH}\left(49-52 \mathrm{~mJ} \mathrm{~m}^{-2}\right)$. The surface energy of all modified GENMS increased in range of $18.2 \%$ to $39.2 \%$ compared to the neat GENMS. The water contact angle of modified GENMS with $\mathrm{NaOH} /$ ethanol and higher concentration for both $\mathrm{NaOH}$ and $\mathrm{NaOH} /$ ethanol (from 0.15 to 0.35 ), show lower contact angle owing to the enriched hydrophilic polar of hydroxyl $(\mathrm{OH})$ and carboxylic acid $(\mathrm{COOH})$ terminal groups. In addition, the improvement of surface hydrophilicity 
and surface energy may be attributed to the increase of the surface roughness as discussed in morphology part. Thus, it was noted that additional ethanol in alkaline hydrolysis treatment improved the hydrophilicity of the GENMS surfaces.

Figure 7 shows the results of protein adsorption on neat GENMS and modified GENMS. It could be observed that modified GENMS with $\mathrm{NaOH}$ showed higher ability to bind BSA molecules than modified GENMS with $\mathrm{NaOH}$ /ethanol while neat GENMS has the highest protein adsorption. Less hydrophilicity of modified GENMS with $\mathrm{NaOH}$ played a major role in more protein adsorption at the interface. It is generally understood that hydrophilic surfaces are more resistant to proteins compared to hydrophobic surfaces. ${ }^{9,18}$ Therefore, more hydrophilicity presented by GENMS with $\mathrm{NaOH} /$ ethanol proved that the existing functional group repelled the protein adsorption and consequently a low degree of denaturation obtained.

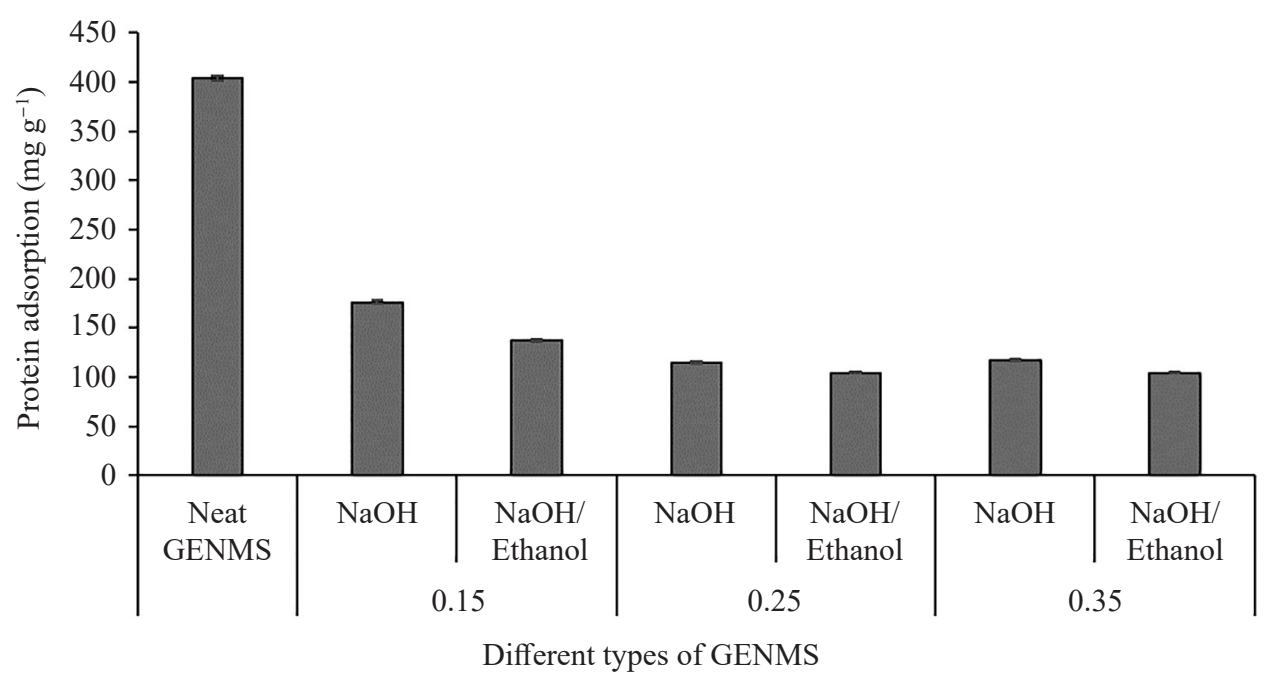

Figure 7: BSA adsorption on neat GENMS and modified GENMS with $\mathrm{NaOH}$ and $\mathrm{NaOH} /$ ethanol at different alkali concentrations of $0.15 \mathrm{M}, 0.25 \mathrm{M}$ and $0.35 \mathrm{M}$.

The percentage of encapsulation efficiency and drug loading of GEN in GENMS was determined based on standard curve of gentamicin concentration $(10-400 \mathrm{ppm})$ as shown in Figure 3. Table 2 presents the encapsulation efficiency (\%) and drug loading (\%) of neat GENMS and modified GENMS. From the calculation, the average encapsulation efficiency and drug loading of GENMS were $13.970 \% \pm 0.311$ and $0.028 \% \pm 0.001$, respectively. Encapsulation efficiency can be defined as the percentage of the ratio of mass drug encapsulated to the mass of drug loaded in the emulsion. The drug loading is related to the drug contained 
in certain mass of microspheres. Since GEN is a very hydrophilic drug, it tends to come out into water phase when microsphere are fabricated using ESE method which probably made the obtained encapsulation low. ${ }^{19}$

In overall, higher encapsulation efficiency and drug loading is observed for the modified GENMS with NaOH/ethanol compared to modified GENMS with $\mathrm{NaOH}$. As expected, both modifications show lower encapsulation efficiency and drug loading than neat GENMS. The differences of encapsulation efficiency and drug loading between modification with $\mathrm{NaOH} /$ ethanol and $\mathrm{NaOH}$ were determined and shown by percentage value in Table 2. Interestingly, even though more hydrophilicity was created by $\mathrm{NaOH} /$ ethanol during hydrolysis, the encapsulation efficiencies of modified GENMS were not reduced. For example, encapsulation efficiency and drug loading of GENMS with $0.35 \mathrm{M} \mathrm{NaOH} /$ ethanol increased $3.98 \%$ and $4.37 \%$, respectively compared to $\mathrm{NaOH}$ modification. This is probably due to hydrolysis with $0.15-0.35 \mathrm{M} \mathrm{NaOH} / \mathrm{ethanol} \mathrm{that} \mathrm{changed} \mathrm{the}$ GENMS by surface erosion reaction without bulk degradation. This is supported by rougher surfaces of modified GENMS with $\mathrm{NaOH} /$ ethanol as shown in Figure 5 which demonstrated the occurrence of surface erosion. It is well known that, bulk degradation on microspheres during alkaline hydrolysis was not preferable in surface modification because certain amount of GEN might be loss in this process. ${ }^{7} \mathrm{NaOH} /$ ethanol provided rougher surface of GENMS in order to increase encapsulation efficiency.

Table 2: Encapsulation efficiency and drug loading of neat GENMS and modified GENMS.

\begin{tabular}{|c|c|c|c|c|c|c|c|}
\hline \multirow[b]{2}{*}{ GENMS } & \multirow[b]{2}{*}{$\begin{array}{l}\text { Neat } \\
\text { GENMS }\end{array}$} & \multicolumn{6}{|c|}{ Modified GENMS } \\
\hline & & $\begin{array}{l}0.15 \mathrm{M} \\
\mathrm{NaOH}\end{array}$ & $\begin{array}{c}0.15 \mathrm{M} \\
\mathrm{NaOH} / \text { ethanol }\end{array}$ & $\begin{array}{l}0.25 \mathrm{M} \\
\mathrm{NaOH}\end{array}$ & $\begin{array}{c}0.25 \mathrm{M} \\
\mathrm{NaOH} / \text { ethanol }\end{array}$ & $\begin{array}{l}0.35 \mathrm{M} \\
\mathrm{NaOH}\end{array}$ & $\begin{array}{c}0.35 \mathrm{M} \\
\mathrm{NaOH} / \text { ethanol }\end{array}$ \\
\hline $\begin{array}{l}\text { Encapsulation } \\
\text { efficiency (\%) }\end{array}$ & 13.970 & 9.204 & $\begin{array}{l}9.321 \\
(1.27 \%)^{*}\end{array}$ & 9.051 & $\begin{array}{l}9.588 \\
(5.93 \%)\end{array}$ & 8.947 & $\begin{array}{l}9.303 \\
(3.98 \%)\end{array}$ \\
\hline Drug loading (\%) & 0.0280 & 0.0236 & $\begin{array}{c}0.0239 \\
(1.27 \%)\end{array}$ & 0.0232 & $\begin{array}{r}0.0246 \\
(6.03 \%)\end{array}$ & 0.0229 & $\begin{array}{c}0.0239 \\
(4.37 \%)\end{array}$ \\
\hline
\end{tabular}

( )*\% is obtained from the difference between GENMS modified with $\mathrm{NaOH} /$ ethanol and $\mathrm{NaOH}$

In the present study, low alkaline concentrations of $0.15 \mathrm{M}$ to $0.35 \mathrm{M}$ can be applied to avoid severe bulk degradation beside of improving its hydrophilicity and cell affinity. ${ }^{13}$ The degradation might be very fast at highly basic and highly acidic mediums (as compared to neutral conditions). ${ }^{20}$ Therefore, surface modification using $\mathrm{NaOH} /$ ethanol brings out an advantage over modified GENMS since higher encapsulation efficiency is a desired goal for controlled drug release studies. ${ }^{21}$ 
The cumulative GEN release amount by difference encapsulation efficiency which measured by UV-Vis spectrophotometry is shown in Figure 8. The GEN release in PBS solution was measured for over 10 days, which the GEN release behaviour from neat GENMS was used as comparison. The release behaviour of GEN from neat GENMS and modified GENMS (0.15 and 0.25) indicate that all samples have an initial burst release within $7 \mathrm{~h}$. The burst release was in the range of $20 \%-35 \%$ and $28 \%-58 \%$ for modification with $0.15 \mathrm{M}$ and $0.25 \mathrm{M}$, respectively.

Modification with $0.15 \mathrm{M} \mathrm{NaOH} /$ ethanol shows a secondary burst release starting at $72 \mathrm{~h}$ while increasing release rate for modification with $0.25 \mathrm{M} \mathrm{NaOH} /$ ethanol at the same point. Secondary burst release occurred whenever the entrapped GEN was released from interior side of microsphere, which showed the lagging time from $24 \mathrm{~h}$ to $72 \mathrm{~h}$. This phase can be useful for pulsatile immunisation applications. ${ }^{22} \mathrm{In}$ contrast, $0.25 \mathrm{M} \mathrm{NaOH} /$ ethanol which probably has undergone the modification entirely on the surface than low alkaline concentration of $0.15 \mathrm{M}$. Thus, GEN might be released uniformly over the time.

The initial burst release can be explained by the presence of surface associated GEN which is close to the surface and diffused into PBS phase faster as GEN is highly hydrophilic. ${ }^{19}$ This is also supported by previous work that claimed the pores on microsphere surface could help in drug release by diffusion mechanism. ${ }^{23}$
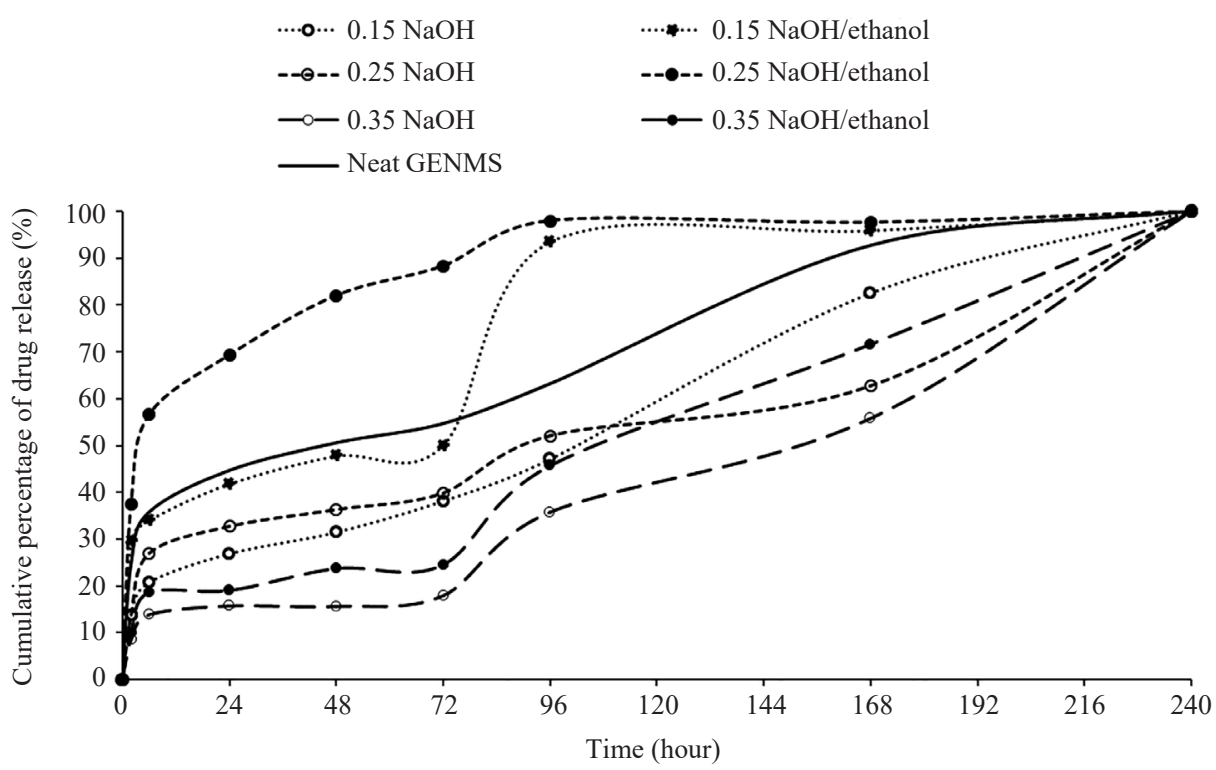

Figure 8: Cumulative GEN release from modified GENMS with $0.15 \mathrm{M}, 0.25 \mathrm{M}$ and $0.35 \mathrm{M}$ concentration of $\mathrm{NaOH}$ and $\mathrm{NaOH} /$ ethanol comparing with neat GENMS after 10 days in PBS. 
However, modification with higher concentration of $0.35 \mathrm{M} \mathrm{NaOH}$ and $0.35 \mathrm{M}$ $\mathrm{NaOH} /$ ethanol presented that the lowest initial burst happened, $12 \%-19 \%$ within $7 \mathrm{~h}$. This is due to low encapsulation efficiency, which had been lost during hydrolysis process. It might also be that the surface associated GEN was diminished using this concentration as alkaline hydrolysis treatment.

Even though initial high burst release rate may cause unfavourable roles, i.e., may lead to drug concentrations near or above the toxic level, excreted without being effectively utilised and wasted, there are still have favourable perspective. ${ }^{22}$ Initial burst releases can provide immediate relief such as those used at the beginning of wound healing followed by prolonged release to promote gradual healing and has ability to localise delivery to the specific site of implantation. ${ }^{24}$

Relating to higher encapsulation efficiency by modified GENMS with $\mathrm{NaOH} / \mathrm{ethanol}$, GEN release rate increased compared with modified GENMS with $\mathrm{NaOH}$. Additionally, more hydrophilicity of modified GENMS with $\mathrm{NaOH} /$ ethanol was also attributed to the increased in GEN release. ${ }^{25}$ This is due to the diffusion path of the surface had been reduced which the drug molecules have to cross. However, based on modification using both $0.15 \mathrm{M}$ and $0.25 \mathrm{M}$, GEN release $0.15 \mathrm{M} \mathrm{NaOH} /$ ethanol and $0.25 \mathrm{M} \mathrm{NaOH} /$ ethanol were higher than neat GENMS and those $0.15 \mathrm{M} \mathrm{NaOH}$ and $0.25 \mathrm{M} \mathrm{NaOH}$, respectively. This is probably the presence of surface associated GEN to diffuse easily than $0.15 \mathrm{M}$ $\mathrm{NaOH}$ and $0.25 \mathrm{M} \mathrm{NaOH}$ and assisted with their higher encapsulation efficiency. In contrast, modification with $0.35 \mathrm{M}$ showed both $0.35 \mathrm{M} \mathrm{NaOH} /$ ethanol and $0.35 \mathrm{M} \mathrm{NaOH}$ have the release rate were than neat GENMS. This might be due to these modification concentrations which had diffused out the encapsulated GEN in modified GENMS during hydrolysis process.

Therefore, the alkaline hydrolysis does not necessarily lead to improve hydrophilicity, in fact co-treating by ethanol had maximised the encapsulation efficiency, thus beneficial in controlling the release profile. It can be suggested that an optimised concentration using alkaline hydrolysis is $0.25 \mathrm{M} \mathrm{NaOH} /$ ethanol for $24 \mathrm{~h}$ treatment. 


\section{CONCLUSION}

The introduction of ethanol in alkaline treatment assisted the hydrolysis using $\mathrm{NaOH}$. Ethanol acts as a co-treating medium in $0.15 \mathrm{M}, 0.25 \mathrm{M}$ and $0.35 \mathrm{M}$ of $\mathrm{NaOH}$. Therefore, the present study concludes that:

(a) Ethanol in $\mathrm{NaOH}$ treatment facilitated the hydroxide nucleophilic attack on the ester bonds and avoiding severe bulk degradation.

(b) Surface roughness of the modified GENMS by $\mathrm{NaOH} /$ ethanol led to the improvement of surface hydrophilicity by $4 \%$ reduction of contact angle compared with $\mathrm{NaOH}$ modification.

(c) Hydrophilicity by $\mathrm{NaOH} /$ ethanol contributed to the low degree of protein adsorption on the GENMS surfaces compared with $\mathrm{NaOH}$ modification.

(d) Encapsulated drug was not reduced even though the hydrophilicity was improved by $\mathrm{NaOH} /$ ethanol. The encapsulation efficiencies increased up to $6 \%$ compared to that modification done by $\mathrm{NaOH}$.

(e) $0.25 \mathrm{M} \mathrm{NaOH} /$ ethanol was suggested as a suitable mixture for alkaline treatment due to the difference on encapsulation efficiency (\%) and drug loading (\%) comparing to $0.25 \mathrm{M} \mathrm{NaOH}$ as well as greater drug release rate.

\section{ACKNOWLEDGEMENTS}

The authors acknowledge the support from the Ministry of Education Malaysia through the Trans Disciplinary Research Grant Scheme (TRGS 6761004). The authors also gratefully acknowledge support from the Universiti Sains Malaysia and Biomaterials Niche Area Group, School of Materials and Mineral Resources Engineering, Pulau Pinang, Malaysia.

\section{REFERENCES}

1. Shah, R. et al. (2014). Optimisation and stability assessment of solid lipid nanoparticles using particle size and zeta potential. J. Phys. Sci., 25(1), 59-75.

2. Son, J. S. et al. (2011). Porous hydroxyapatite scaffold with three-dimensional localized drug delivery system using biodegradable microspheres. J. Contr. Rel., 153(2), 133-140, https://doi.org/10.1016/j.jconrel.2011.03.010.

3. Ramazani, F. et al. (2016). Strategies for encapsulation of small hydrophilic and amphiphilic drugs in PLGA microspheres: State-of-the-art and challenges. Int. J. Pharm., 499(1-2), 358-367, https://doi.org/10.1016/j.ijpharm.2016.01.020. 
4. Shi, X. et al. (2011). Hydrolysis and biomineralization of porous PLA microspheres and their influence on cell growth. Coll. Surf. B Biointerf., 85(1), 73-80, https://doi.org/10.1016/j.colsurfb.2010.11.016.

5. Huang, W. et al. (2014). Microsphere based scaffolds for bone regenerative applications. Biomater. Sci., 2(9), 1145-1153, https://doi.org/10.1039/C4BM $00161 \mathrm{C}$.

6. Dorati, R. et al. (2017). Biodegradable scaffolds for bone regeneration combined with drug-delivery systems in osteomyelitis therapy. Pharm., 10(4), https://doi. org/10.3390/ph10040096.

7. Li, H. et al. (2013). 25-Hydroxyvitamin D (3)-loaded PLA microspheres: In vitro characterization and application in diabetic periodontitis models. AAPS PharmSciTech., 14(2), 880-889, https://doi.org/10.1208/s12249-013-9978-5.

8. Da Silva, D. et al. (2018). Biocompatibility, biodegradation and excretion of polylactic acid (PLA) in medical implants and theranostic systems. Chem. Eng. J., 340, 9-14, https://doi.org/10.1016/j.cej.2018.01.010.

9. Vogler, E. A. (2012). Protein adsorption in three dimensions. Biomater., 33(5), 1201-1237, https://doi.org/10.1016/j.biomaterials.2011.10.059.

10. Ghorbanpour, M. (2016). Amine accessibility and chemical stability of Silver SPR Chips silanised with APTES via vapour phase deposition method. J. Phys. Sci., 27(1), 39-51.

11. Hosseini, S. et al. (2014). Recent advances in surface functionalization techniques on polymethacrylate materials for optical biosensor applications. Anal., 139(12), 2933-2943, https://doi.org/10.1039/c3an01789c.

12. Araujo, J. V. et al. (2008). Surface controlled biomimetic coating of polycaprolactone nanofiber meshes to be used as bone extracellular matrix analogues. J. Biomater. Sci. Polym. Ed., 19(10), 1261-78, https://doi.org/10.1163/ 156856208786052335.

13. Yang, J. et al. (2003). Enhancing the cell affinity of macroporous poly(L-lactide) cell scaffold by a convenient surface modification method. Polym. Int., 52(12), 1892-1899, https://doi.org/10.1002/pi.1272.

14. Marchand-Brynaert, J. et al. (1995). Surface functionalization of poly(ethylene terephthalate) film and membrane by controlled wet chemistry: Chemical characterization of carboxylated surfaces. J. Coll. Interf. Sci., 173(1), 236-244, https://doi.org/10.1006/jcis.1995.1319.

15. Swamy, N. G. N., Abbas, Z. \& Praveen, B. (2013). Fabrication and in vitro evaluation of doxycycline loaded chitosan microspheres for the treatment of periodontitis. J. Pharm. Sci., 3(2), 26-32.

16. Rafigh, S. M. et al. (2016). Protein adsorption using novel carboxymethyl-curdlan micropheres. Int. J. Biol. Macromol., 87, 603-610, https://doi.org/10.1016/j. ijbiomac.2016.03.008.

17. Hurwitz, G. et al. (2010). Probing polyamide membrane surface charge, zeta potential, wettability, and hydrophilicity with contact angle measurements. J. Membr. Sci., 349(1-2), 349-357, https://doi.org/10.1016/j.memsci.2009.11.063.

18. Marquetti, I. \& Desai, S. (2018). Molecular modeling the adsorption behavior of bone morphogenetic protein-2 on hydrophobic and hydrophilic substrates. Chem. Phys. Lett., 706, 285-294, https://doi.org/10.1016/j.cplett.2018.06.015. 
19. Naraharisetti, P. K. et al. (2005). Gentamicin-loaded discs and microspheres and their modifications: Characterization and in vitro release. J. Contr. Rel., 102(2), 345-359, https://doi.org/10.1016/j.jconrel.2004.10.016.

20. Elsawy, M. A. et al. (2017). Hydrolytic degradation of polylactic acid (PLA) and its composites. Renew. Sustain. Energy Rev., 79, 1346-1352, https://doi.org/ 10.1016/j.rser.2017.05.143.

21. Sendil, D., Gursel, I. \& Wise, D. L. (1999). Antibiotic release from biodegradable PHBV microparticles. J. Contr. Rel., 59, 207-217, https://doi.org/10.1016/S01683659(98)00195-3.

22. Leach, W. T. et al. (2005). Encapsulation of protein nanoparticles into uniformsized microspheres formed in a spinning oil film. AAPS PharmSciTech, 6(4), E605-E617, https://doi.org/10.1208/pt060475.

23. Ma, Z. et al. (2002). Immobilization of natural macromolecules on polyL-lactic acid membrane surface in order to improve its cytocompatibility. J. Biomed. Mater. Res., 63(6), 838-847, https://doi.org/10.1002/jbm.10470.

24. Huang, X. \& Brazel, C. S. (2001). On the importance and mechanisms of burst release in matrix-controlled drug delivery systems. J. Contr. Rel., 73(2-3), 121136, https://doi.org/10.1016/S0168-3659(01)00248-6.

25. El-Say, K. M. (2016). Maximizing the encapsulation efficiency and the bioavailability of controlled-release cetirizine microspheres using Draper-Lin small composite design. Drug Des. Devel. Ther., 10, 825-839, https://doi.org/10.2147/ DDDT.S101900. 